\section{JTI}

JOURNAL OF

TRAUMA AND INJURY

Received: February 18, 2019

Revised: March 19, 2019

Accepted: March 25, 2019

\section{Correspondence to}

Woo-Kie Min, M.D., Ph.D.

Department of Orthopedic Surgery, Kyungpook National University Hospital, Kyungpook National University School of Medicine, 130 Dongdeok-ro, Jung-gu, Daegu 41944, Korea

Tel: +82-53-200-5628

Fax: +82-52-422-6605

E-mail:wkmin@knu.ac.kr

\title{
Comparison of Magnetic Resonance Imaging and Operation Waiting Times in Patients Having Traumatic Cervical Spinal Cord Injury; with or without Bony Lesions
}

\author{
Jeong Heo, M.D., Woo-Kie Min, M.D., Ph.D., Chang-Wug Oh, M.D., Ph.D., \\ Joon-Woo Kim, M.D., Ph.D., Kyeong-hyeon Park, M.D., Ph.D., Il Seo, M.D., \\ Eung-Kyoo Park, M.D.
}

Department of Orthopedic Surgery, Kyungpook National University Hospital, Kyungpook National University School of Medicine, Daegu, Korea

Purpose: To compare the time intervals to magnetic resonance imaging (MRI) and surgical treatment in patients having traumatic cervical spinal cord injury (SCI) with and without bony lesions.

Methods: Retrospectively analyzed adult patients visited Kyungpook National University Hospital and underwent surgical treatment for cervical SCI within 24 hours. The patients who were suspected of having cervical SCI underwent plain radiography and computed tomography (CT) upon arrival. After the initial evaluation, we evaluated the MRI findings to determine surgical treatment. Waiting times for MRI and surgery were evaluated.

Results: Thirty-four patients were included. Patients' mean age was 57 (range, 23-80) years. Patients with definite bony lesions were classified into group $\mathrm{A}$, and 10 cases were identified (fracture-dislocation, seven; fracture alone, three). Patients without bony lesions were classified into group B, and 24 cases were identified (ossification of the posterior longitudinal ligament, 16; cervical spondylotic myelopathy, eight). Mean intervals between emergency room arrival and start of MRI were $93.60( \pm 60.08)$ minutes in group $A$ and $313.75( \pm 264.89)$ minutes in group B, and the interval was significantly shorter in group A than in group B $(p=0.01)$. The mean times to surgery were $248.4( \pm 76.03)$ minutes in group A and $560.5( \pm 372.56)$ minutes in group B, and the difference was statistically significant $(p=0.001$ ). The American Spinal Injury Association scale at the time of arrival showed that group A had a relatively severe neurologic deficit compared with group B $(p=0.046)$. There was no statistical significance, but it seems to be good neurological recovery, if we start treatment sooner among patients treated within 24 hours $(p=0.198)$. Conclusions: If fracture or dislocation is detected by CT, cervical SCI can be easily predicted resulting in MRI and surgical treatment being performed more rapidly. Additionally, fracture or dislocation tends to cause more severe neurological damage, so it is assumed that rapid diagnosis and treatment are possible.

Keywords: Spinal cord injuries; Retrospective studies; Spinal injuries; Diagnosis 


\section{INTRODUCTION}

The incidence of traumatic spinal cord injuries (SCIs) in the United States is approximately 54 per million people; around 17,700 cases, excluding those that involve deaths at the scene of the accident, occur annually [1].

Damage at the level of the cervical spine is the most common type of SCI and is associated with a high mortality rate [2]. The development of computed tomography (CT) and magnetic resonance imaging (MRI) has aided in the diagnosis and evaluation of SCIs [3]. Among adult patients with SCIs, 75\% were reported to have fracture dislocation, dislocation only, or a burst fracture, and 25\% of patients had only minor fractures without definite lesions (including compression fracture), SCI without radiological abnormality, and SCI without obvious radiological evidence of trauma [4]. In the presence of cervical spinal stenosis, traumatic SCI may occur without fracture or dislocation [5]. The most common cause of cervical spinal stenosis is cervical ossification of the posterior longitudinal ligament (OPLL) and cervical spondylotic myelopathy (CSM) [6-8]. In cervical spinal stenosis, the anteroposterior diameter of the spinal canal is a significant risk factor for the development of SCI [8-10].

If cervical SCI occurs, surgical treatment within 24 hours is reported to improve the prognosis [11-13]. The role of MRI in diagnosing and treating SCI is very important $[14,15]$; in particular, if there is cervical spinal stenosis without bony fracture or dislocation, MRI plays an essential role in deciding the mode of surgical treatment. In this study, we retrospectively compared the time intervals to MRI and surgical treatment in patients with a cervical SCI with and without definite bony lesions detected using CT. We hypothesized that MRI imaging and treatment would be delayed in patients with spinal cord injuries that are not readily diagnosed by $\mathrm{CT}$.

\section{METHODS}

We retrospectively analyzed patients who had been diagnosed with SCI and underwent surgical treatment from 2012 to 2018 in Kyungpook National University Hospital. The inclusion criteria were adult patients aged between
18 and 80 years and a neurological level of injury between $\mathrm{C} 2$ and T1. The exclusion criteria were patients with a high degree of instability in whom it was impossible to use MRI, those in whom it was difficult to perform an accurate neurological examination (e.g., patients with concomitant brain hemorrhage, a history of previous neurological deficit, and combined fracture of the extremity), those who were transferred to Kyungpook National University Hospital after radiological evaluation, and those in whom surgical treatment within 24 hours could not be performed.

If patients were suspected of having cervical SCI, CT was performed immediately in the emergency room followed by a neurological examination. The neurological status at the time of arrival to the emergency room was evaluated using the American Spinal Injury Association (ASIA) impairment scale. If cervical SCI was suspected, MRI was performed preoperatively. CT and MRI findings were analyzed using the Picture Archiving and Communication System ( $\pi$ view; Infinitt, Seoul, Korea).

The time interval between arrival to the emergency room and initiation of the MRI and emergency operation was calculated from the medical records. Patients were divided into two groups, those with definite bony lesions (with fracture-dislocation or fracture only detected by CT) and those without definite lesions.

This study was approved by Kyungpook National University Hospital Institutional Review Board (IRB No. 2018-12-014).

\section{Statistical analysis}

For statistical analysis, SPSS 17.0 (SPSS, Inc., Chicago, IL, USA) was used. Data was tested for normality and the independent $t$-test was used to analyze differences between the two patient groups. A $p$-value $<0.05$ was considered statistically significant.

\section{RESULTS}

Thirty-four patients were included in the study. The patients' mean age at the time of injury was 57 (range, 23-80) years, and the male-to-female ratio was $31: 3$. Ten patients with definite bony lesions (fracture-dislocation, 
seven; fracture only, three) were identified and classified into group A (Fig. 1). Twenty-four patients without bony lesions (OPLL, 16; CSM, eight) were identified and classified into group B (Fig. 2). The time intervals from arrival to the emergency room to the time of MRI were 93.60 $( \pm 60.08)$ mins in group A and $313.75( \pm 264.89)$ mins in group $\mathrm{B}$. The time to MRI was significantly shorter in
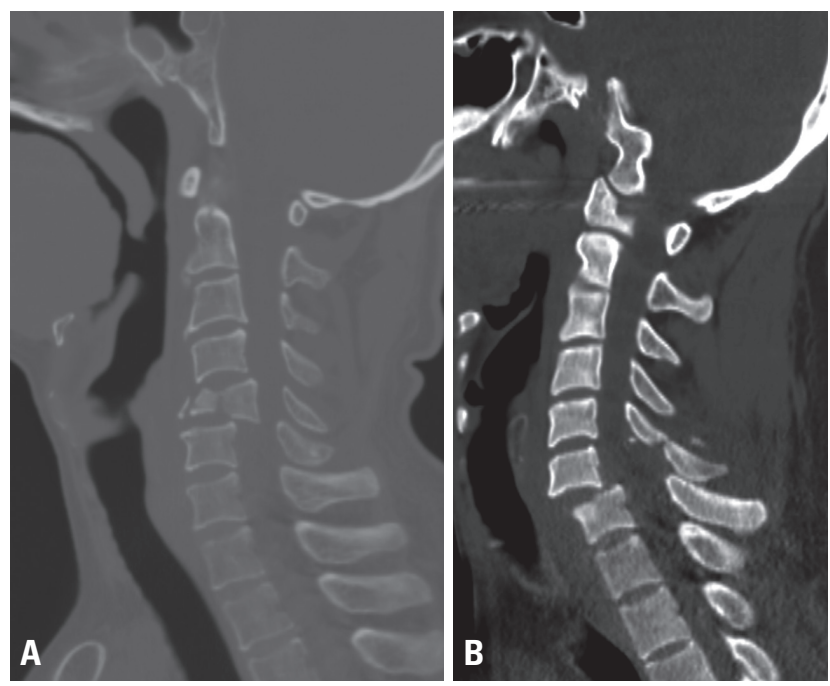

Fig. 1. Computed tomography images of spinal cord injury with bony lesion (A) with burst fracture. (B) With fracture-dislocation injury.
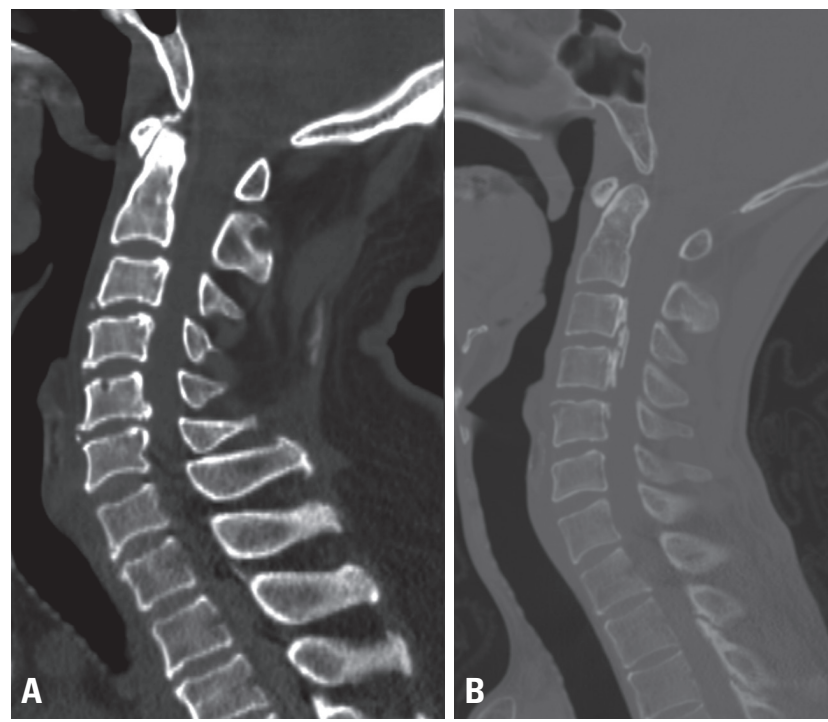

Fig. 2. Computed tomography images of spinal cord injury without bony lesion (A) with cervical spondylotic myelopathy. (B) With ossification of the posterior longitudinal ligament. group A than in group B (independent $t$-test, $p=0.01$ ). The times to surgery were 248.40 minutes $( \pm 76.03)$ in group A and 560.50 minutes $( \pm 372.56)$ in group $\mathrm{B}$. The time to start of surgical treatment was significantly shorter in group A than in group B (independent $t$-test, $p=0.001$ ). In both groups, the times to MRI and surgical treatment followed a normal distribution (Table 1).

The ASIA impairment scale grades in group $\mathrm{A}$ at the time of arrival in the emergency room were $\mathrm{A}$ in four patients, $B$ in three patients, $C$ in two patients, and $D$ in one patient. The ASIA impairment scale grades in group $B$ were $A$ in five patients, $B$ in three, $C$ in five, and $D$ in 11 . The independent-sample $t$-test showed that in comparison to patients in group B, those in group A had a statistically significant tendency to have severe neurologic deficits ( $p=0.0468$ ) (Table 2).

In group $A$, all patients except one case underwent surgical treatment within 6 hours of arrival (248.40 [ \pm 76.03$]$ minutes). In Group B, 14 patients underwent surgical treatment within 6 hours (mean, 264.40 57.54 minutes), and ten patients underwent surgical treatment

Table 1. Time intervals to MRI and surgical treatment

\begin{tabular}{|ccc|}
\hline & Time to MRI (minutes) & $\begin{array}{c}\text { Time to surgical } \\
\text { treatment (minutes) }\end{array}$ \\
\hline${\text { Group } A^{\mathrm{a}}}^{\mathrm{a}}$ & $93.60( \pm 60.08)$ & $313.75( \pm 264.89)$ \\
Group B $^{\mathrm{b}}$ & $248.4( \pm 76.03)$ & $560.5( \pm 372.56)$ \\
\hline
\end{tabular}

The times to MRI ( $p=0.01)$ and surgical treatment $(p=0.001)$ were signifcantly shorter in group A than in group B.

MRl: magnetic resonance imaging.

aPatients with bony lesions.

${ }^{b}$ Patients without bony lesions.

Table 2. ASIA scale levels in each group

\begin{tabular}{|lcc|}
\hline & Group A $^{\text {a }}$ & Group B $^{\text {b }}$ \\
\hline A & $4(40 \%)$ & $5(20.8 \%)$ \\
B & $3(30 \%)$ & $3(12.5 \%)$ \\
\hline D & $2(20 \%)$ & $5(20.8 \%)$ \\
\hline
\end{tabular}

The neurological deficit was more severe in group A than in group $B$, with statistical significance ( $p=0.0468)$.

ASIA: American Spinal Injury Association.

aPatients with bony lesions.

${ }^{b}$ Patients without bony lesions. 
between 6 and 24 hours (mean, 900.30 \pm 287.64 minutes). In group A, six cases (60\%) showed postoperative improvement of neurological status, as measured by the ASIA scale; however, the other four cases (40\%) remained unchanged. In group B, 11 cases $(45.8 \%)$ showed recovery of the ASIA scale and 13 cases (54.2\%) showed no change. When looking specifically at the 14 cases of surgical treatment within 6 hours in group B, eight cases $(57.1 \%)$ showed an improvement in the ASIA scale whereas six cases $(42.9 \%)$ showed no change. However, in the patients who underwent surgical treatment within 6 to 24 hours, the ASIA scale improved in three patients and seven showed no change. Therefore, in group B, there was no significant difference in the recovery of neurological status according to the difference in operative treatment delay time $(p=0.198)$ (Table 3$)$.

\section{DISCUSSION}

In order to ensure early surgical treatment SCIs, imaging studies are necessary, followed by an MRI; however, MRI is usually time consuming. In general, MRI evaluation is performed according to the priority of the injury. If MRI is delayed, the time interval to starting surgical treatment tends to be longer.

This study found that the time to perform MRI in the group without bony lesion was significantly longer resulting in surgical treatment being delayed. Although no statistical significance was shown, in the group without bony lesions, surgical treatment within 6 hours tended to result

Table 3. Recovery of ASIA scale in each group

\begin{tabular}{|lccc|}
\hline & $\begin{array}{c}\text { Group A } \\
(\mathbf{n}=10)\end{array}$ & $\begin{array}{c}\text { Group B }^{\text {b }} \\
(<6 \text { hours }) \\
(\mathbf{n}=14)\end{array}$ & $\begin{array}{c}\text { Group B }^{\text {b }} \\
(\mathbf{6}-24 \text { hours }) \\
(\mathbf{n}=10)\end{array}$ \\
\hline Recovered & $6(60 \%)$ & $8(57.1 \%)$ & $3(30 \%)$ \\
No change & $4(40 \%)$ & $6(42.9 \%)$ & $7(70 \%)$ \\
\hline
\end{tabular}

In group B, patients treated within 6 hours tended to recover more than patients who were treated between 6 and 24 hours, although this was not statistically significant ( $p=0.198)$.

ASIA: American Spinal Injury Association.

aPatients with bony lesions.

${ }^{b}$ Patients without bony lesions. in increased recovery of neurological symptoms. Therefore, our results indicate that outcomes were more favorable if surgical treatment is performed relatively quickly, even within 24 hours.

$\mathrm{CT}$ is one of the most common imaging modalities that can be performed immediately in the emergency room. When a bony lesion is detected via CT, it is easy to assume that cervical SCI is present, and the examination is likely

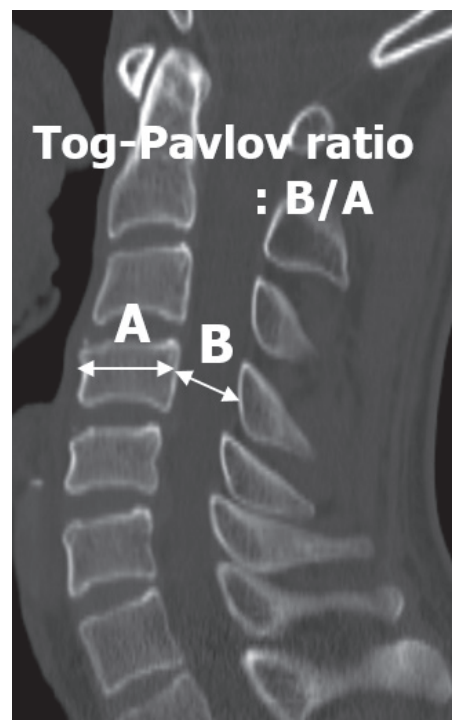

Fig. 3. Torg-Pavlov ratio: B/A. Anteroposterior diameter of the vertebral body, A. Anteroposterior diameter of the spinal canal, B.

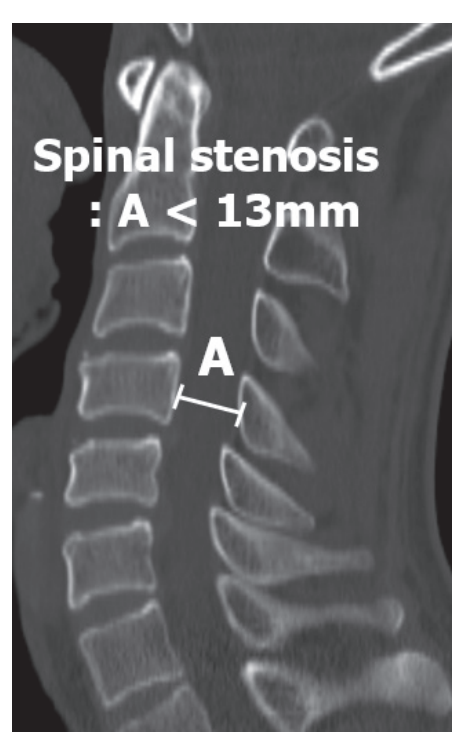

Fig. 4. Anteroposterior diameter of the spinal canal, A. If $A<13$ mm, spinal stenosis if highly suspected. 
to proceed more rapidly. In addition, bony lesions are significantly more likely to be associated with neurological symptoms, which may help to predict cervical SCI. In the absence of bony lesions, cervical SCI occurs mainly when OPLL or CSM is present [5-8].

The Torg-Pavlov ratio is the value of the anteroposterior diameter of the spinal canal at the mid-vertebral level divided by the anteroposterior diameter of the vertebral body at the same level [16,17] (Fig. 3). Normally, the ratio is 1.0 , but if the value is smaller, it is possible that cervical spinal stenosis is underway. In particular, when the ratio is less than 0.7, it has been reported that cervical spinal stenosis is related to SCI [18]. Additionally, if the midsagittal canal diameter is less than $13 \mathrm{~mm}$ at the $\mathrm{C} 3$ to $\mathrm{C} 7$ level, cervical spinal stenosis is often suspected [19] (Fig. 4). In patients without bony lesions, such as fracture-dislocation and suspected cervical SCI, the Torg-Pavlov ratio or midsagittal canal diameter should be measured to determine if there is a risk factor for the development of SCI, and MRI should be performed more rapidly so that surgical treatment can be performed early.

This study has several limitations. First, the level of cervical SCI was not considered. Second, age, sex, neurological status, and underlying disease were not controlled for in the patient groups. Third, there may be a difference in the protocol for evaluating SCI patients in other institutes; therefore, it is difficult to interpret these results as representative of all SCI patients.

\section{CONCLUSION}

If fracture or dislocation is detected by CT, cervical SCI can be easily predicted resulting in MRI and surgical treatment being performed more rapidly. Our results suggest that surgical treatment within 6 hours is likely to result in increased neurological symptom recovery, although this finding was not significant. Further studies are required to explore this association further.

\section{REFERENCES}

1. National Spinal Cord Injury Statistical Center. Spinal cord in- jury facts and figures at a glance [Internet]. Birmingham: University of Alabama at Birmingham 2016 [cited 2018 Dec 24]. Available from: https://www.nscisc.uab.edu/Public/Facts $\% 20$ 2016.pdf.

2. Kraus J, Silberman T, McArthur D. Epidemiology of spinal cord injury. Principles of spinal surgery. New York: McGraw-Hill; 1996:41-58.

3. Fehlings MG, Rao SC, Tator CH, Skaf G, Arnold P, Benzel E, et al. The optimal radiologic method for assessing spinal canal compromise and cord compression in patients with cervical spinal cord injury. Part II: results of a multicenter study. Spine 1999;24:605-13.

4. Sekhon LH, Fehlings MG. Epidemiology, demographics, and pathophysiology of acute spinal cord injury. Spine 2001;26 (24 Suppl):S2-12.

5. Epstein N, Epstein JA, Benjamin V, Ransohoff J. Traumatic myelopathy in patients with cervical spinal stenosis without fracture or dislocation: methods of diagnosis, management, and prognosis. Spine 1980;5:489-96.

6. Bernhardt M, Hynes RA, Blume HW, White AA 3rd. Cervical spondylotic myelopathy. J Bone Joint Surg Am 1993;75:119-28.

7. Katoh S, Ikata T, Hirai N, Okada Y, Nakauchi K. Influence of minor trauma to the neck on the neurological outcome in patients with ossification of the posterior longitudinal ligament (OPLL) of the cervical spine. Paraplegia 1995;33:330-3.

8. Moiel RH, Raso E, Waltz TA. Central cord syndrome resulting from congenital narrowness of the cervical spinal canal. J Trauma 1970;10:502-10.

9. Eismont FJ, Clifford S, Goldberg M, Green B. Cervical sagittal spinal canal size in spine injury. Spine 1984;9:663-6.

10. Matsuura P, Waters RL, Adkins RH, Rothman S, Gurbani N, Sie I. Comparison of computerized tomography parameters of the cervical spine in normal control subjects and spinal cordinjured patients. J Bone Joint Surg Am 1989;71:183-8.

11. Fehlings MG, Vaccaro A, Wilson JR, Singh A, W Cadotte D, Harrop JS, et al. Early versus delayed decompression for traumatic cervical spinal cord injury: results of the surgical timing in acute spinal cord injury study (STASCIS). PloS One 2012;7:e32037.

12. La Rosa G, Conti A, Cardali S, Cacciola F, Tomasello F. Does early decompression improve neurological outcome of spinal cord injured patients? Appraisal of the literature using a metaanalytical approach. Spinal Cord 2004;42:503-12.

13. Lee DY, Park YJ, Song SY, Hwang SC, Kim KT, Kim DH. The 
importance of early surgical decompression for acute traumatic spinal cord injury. Clin Orthop Surg 2018;10:448-54.

14. Fehlings MG, Martin AR, Tetreault LA, Aarabi B, Anderson P, Arnold PM, et al. A clinical practice guideline for the management of patients with acute spinal cord injury: recommendations on the role of baseline magnetic resonance imaging in clinical decision making and outcome prediction. Global Spine J 2017;7(3 Suppl):221S-30S.

15. Bozzo A, Marcoux J, Radhakrishna M, Pelletier J, Goulet B. The role of magnetic resonance imaging in the management of acute spinal cord injury. J Neurotrauma 2011;28:1401-11.

16. Torg JS, Pavlov H, Genuario SE, Sennett B, Wisneski RJ, Robie $\mathrm{BH}$, et al. Neurapraxia of the cervical spinal cord with transient quadriplegia. J Bone Joint Surg Am 1986;68:1354-70.

17. Pavlov H, Torg JS, Robie B, Jahre C. Cervical spinal stenosis: determination with vertebral body ratio method. Radiology 1987;164:771-5.

18. Aebli N, Wicki AG, Rüegg TB, Petrou N, Eisenlohr H, Krebs J. The Torg-Pavlov ratio for the prediction of acute spinal cord injury after a minor trauma to the cervical spine. Spine J 2013;13:605-12.

19. Morishita $Y$, Naito M, Hymanson H, Miyazaki M, Wu G, Wang JC. The relationship between the cervical spinal canal diameter and the pathological changes in the cervical spine. Eur Spine J 2009;18:877-83. 